\title{
Urinary nerve growth factor correlates with the severity of urgency and pain: methodological evaluation
}

\author{
Mehmet Agilli • Fevzi Nuri Aydin • \\ Yasemin Gulcan Kurt • Tuncer Cayci
}

Published online: 22 October 2014

(C) The International Urogynecological Association 2014

Dear Editor,

We read with great interest the article by Kim et al. entitled with "Urinary nerve growth factor correlates with the severity of urgency and pain" [1]. The authors suggested that urinary nerve growth factor (NGF) levels increase with increasing severity of urgency and are significantly higher in patients with an overactive bladder and in those with bladder pain syndrome/interstitial cystitis than in control patients and those with frequency. However, we think that some points need to be discussed.

The exclusion criteria for the study group were quite restrictive. We think the authors should also have stated whether the patients had one of the following diseases which could affect NGF levels: neuropsychiatric diseases such as epilepsy, depression, schizophrenia, migraine, primary headache and eating disorders, or cardiometabolic diseases such as atherosclerosis, metabolic syndrome and type 2 diabetes mellitus [2].

Bullo et al. found that obesity is one of the factors affecting NGF levels [3]. In this study, the participants' weight and in particular their body mass index (BMI) were not defined. Differences in urinary NGF levels among the study groups could have been caused by differences in these variables. Also a multivariate logistic regression analysis including the

A response to these comments can be found at doi: 10.1007/s00192-0142533-4.

\section{Agilli $(\triangle)$}

Department of Biochemistry, Agri Military Hospital, Agri, Turkey

e-mail: mehmetagilli@yahoo.com

F. N. Aydin

Department of Biochemistry, Sirnak Military Hospital, Sirnak,

Turkey

Y. G. Kurt • T. Cayci

Department of Medical Biochemistry, Gulhane Military Medical

Academy, Ankara, Turkey variables age, sex and BMI could have been applied to establish the relationship between urinary NGF levels and the severity of urgency.

Taking into account the differences in the mean ages of the study groups, there could also have been differences in the medications used for their possible illnesses. Supplements such as vitamin D analogues, zinc, vitamin B12, vitamin A and omega 3 fatty acids or herbal medicines and some drugs such as estrogen, glucocorticoids, acetyl-L-carnitine and antipsychotics can affect NGF levels [4, 5], and whether the participants were using these medications should have been stated.

In conclusion, addressing these concerns would certainly provide more clarity for readers.

Conflicts of interest The authors declare that they have no conflict of interest and no competing financial interest.

\section{References}

1. Kim SW, Im YJ, Choi HC, Kang HJ, Kim JY, Kim JH (2014) Urinary nerve growth factor correlates with the severity of urgency and pain. Int Urogynecol J. doi:10.1007/s00192-014-2424-8

2. Chaldakov GN, Tonchev AB, Aloe L (2009) NGF and BDNF: from nerves to adipose tissue, from neurokines to metabokines. Riv Psichiatr 44(2):79-87

3. Bullo M, Peeraully MR, Trayhurn P, Folch J, Salas-Salvado J (2007) Circulating nerve growth factor levels in relation to obesity and the metabolic syndrome in women. Eur J Endocrinol 157(3):303-310. doi:10.1530/EJE-06-0716

4. Lee JC, Pak SC, Lee SH, Lim SC, Bai YH, Jin CS, Kim JS, Na CS, Bae CS, Oh KS, Choi BC (2003) The effect of herbal medicine on nerve growth factor in estradiol valerate-induced polycystic ovaries in rats. Am J Chin Med 31(6):885-895. doi:10.1142/S0192415X03001636

5. Mocchetti I, Spiga G, Hayes VY, Isackson PJ, Colangelo A (1996) Glucocorticoids differentially increase nerve growth factor and basic fibroblast growth factor expression in the rat brain. J Neurosci 16(6): 2141-2148 